\title{
Influence of short-term surface temperature dynamics on tree orchards energy balance fluxes
}

\author{
Juan Miguel Ramírez-Cuesta ${ }^{1}$ (i) . Simona Consoli ${ }^{2} \cdot$ Domenico Longo $^{2}$. \\ Giuseppe Longo-Minnolo ${ }^{3} \cdot$ Diego S. Intrigliolo $^{1} \cdot$ Daniela Vanella $^{2}$
}

Accepted: 5 February 2022 / Published online: 5 March 2022

(C) The Author(s) 2022

\begin{abstract}
Land surface temperature (LST) plays an essential role in developing and applying precision agriculture protocols, especially for calculating crop evapotranspiration $\left(\mathrm{ET}_{\mathrm{c}}\right)$ by surface energy balance (SEB) approaches; and for determining crop water status. However, LST is quite dependent on the meteorological conditions, which can rapidly vary. This variability, together with the limited meterological data acquisition frequency in most weather stations, can lead to the miscalculation of the SEB components, especially relevant when used for irrigation purposes.

The present study assessed the temporal dynamic of LST in a very short period of time (20-minutes) through the acquisition of multiple thermal imagery. Additionally, a combination of SEB approach with Eddy Covariance technique was performed for quantifying the effect that LST variations have on the sensible (H) and latent (LE) heat fluxes.

Even under steady meteorological conditions, temporal variations in LST of 3.5 and $4.0 \mathrm{~K}$ were observed for tree canopy and sunny bare soil surfaces, respectively. These LST oscillations reached values of about 7.8 and $17.9 \mathrm{~K}$ for tree canopies and bare soil when heterogeneous meteorological conditions were observed (i.e. cloud presence). Such LST differences translated into $\mathrm{H}$ and LE differences of about 26 and $19 \%$, respectively; with variations up to 5 (for $\mathrm{H}$ ) and 2.7 times (for LE) under fast-varying meteorological conditions.

The obtained results suggest the necessity of acquiring thermal imagery when steady meteorological conditions exist or, otherwise, ensuring the collection of instantaneous meteorological data for applying post-processing corrections. This is of importance when incorporating the obtained $\mathrm{ET}_{\mathrm{c}}$ maps into precision irrigation protocols.
\end{abstract}

Keywords Thermal data - Surface temperature variations $\cdot$ Evapotranspiration $\cdot$ Eddy covariance

Extended author information available on the last page of the article 


\section{Introduction}

An accurate determination of crop evapotranspiration $\left(\mathrm{ET}_{\mathrm{c}}\right)$ is essential for increasing the productivity of irrigated agriculture (Filgueiras et al., 2019; Gong et al., 2019). Generally, $\mathrm{ET}_{\mathrm{c}}$ can be determined using measurement or estimation methods (Rana \& Katerji, 2000). Measurement methods can be "direct" if the $\mathrm{ET}_{\mathrm{c}}$ value is quantified using an instrument (e.g., eddy covariance (EC); lisimetry or scintillometry) or "indirect" if the approach considers the relationship among other parameters (e.g. sap flow or water balance techniques). The accuracies and the advantages/disadvantages of these techniques are widely discussed by Allen et al., (2011). As examples, EC and scintillometry methods use sophisticated and expensive instruments that require accurate installation and in field maintenance activities. Lysimeter and sap flow techniques provide point-based values of $\mathrm{ET}_{\mathrm{c}}$ that could not be representative of the whole area of interest. Even for large lysimeter, the representativeness of $\mathrm{ET}_{\mathrm{c}}$ measured is dependent on different crop densities and heights, root characteristics, soil water and nutrient status and soil profile structures between the internal and external part of the lysimeters (Allen et al., 2011). On the other hand, the estimation methods are mainly based on models (including energy balance, mass transfer, and the use of crop coefficients, $\mathrm{K}_{\mathrm{c}}$ ) characterized by different levels of complexity in terms of number of parameters implied for the $\mathrm{ET}_{\mathrm{c}}$ schematization. Some of these models have been combined with remote sensing (RS) information in order to obtain spatially distributed $\mathrm{ET}_{\mathrm{c}}$ estimates over wide areas (Paço et al., 2014; Ramírez-Cuesta et al., 2020; Consoli \& Vanella 2014a, b).

RS estimation methods are usually based on two different approaches: the vegetation indexes (VI) and the surface energy balance (SEB) models. A review of different satellitebased $\mathrm{ET}_{\mathrm{c}}$ approaches is discussed by Zhang et al., (2016). In general, VI approaches are based on the FAO-56 approach (Allen et al., 1998) for deriving the $\mathrm{K}_{\mathrm{c}}$ (i.e. single and double $\mathrm{K}_{\mathrm{c}}$ ), and thus $\mathrm{ET}_{\mathrm{c}}$, from empirical site-specific relationships between the vegetation fraction cover and the canopy reflectance in the visible (VIS) and near-infrared (NIR) regions of the electromagnetic spectrum together with ancillary soil and weather data (Longo-Minnolo et al., 2020; Ramírez-Cuesta et al., 2019). Conversely, SEB models determine $\mathrm{ET}_{\mathrm{c}}$ as a residual of the land SEB equation on the basis of the energy conservation principle. Spatially distributed SEB models are generally coupled with land surface temperature (LST) remotely sensed from thermal infra-red (TIR) imagery data based on radiative transfer models, including also VIS/NIR information and ground-based data. Several schematizations are given in literature for describing the parameters involved in SEB schemes (Zhang et al., 2016). These schemes mainly differ for the state of the overlying atmosphere and the belowing soil water content and for the roughness and thermal properties of the land surface, considering its complexity in terms of density and type of the vegetation cover. Some examples of SEB approaches application in semi-arid areas are reported by Maltese et al., (2018) and Vanella \& Consoli (2018).

In SEB models, the accuracy on the estimation of the LST plays a critical role in determing realible instantaneous $\mathrm{ET}_{\mathrm{c}}$ fluxes. Usually, the hypothesis of daytime self-preservation of the evaporative fraction is considered for estimating daily $\mathrm{ET}_{\mathrm{c}}$ values (Crago, 1996; Allen et al., 2007b). According to this hypothesis, the fraction of available energy used for the latent heat flux (LE) process is considered constant during diurnal hours. Thus, instantaneous LE values are assumed to be representative of the daily values for determining $\mathrm{ET}_{\mathrm{c}}$. The magnitude and temporal variation of LST is generally determined by the conductive, convective, 
and radiative energy exchange process at the Earth atmosphere interface in response to the solar radiation and surface characteristics. Accurate LST retrieval from remotely sensed TIR data depends on atmospheric effects, sensor parameters (i.e., spectral range and viewing angle) and surface parameters, such as land surface emissivity and geometry. LST is a fundamental thermodynamic state variable and represents one of the most important energy driven factor in many eco-hydrological processes occurring at the land-atmosphere interface (Leinonen \& Jones, 2004; Sepulcre-Cantó et al., 2006; Ramírez-Cuesta et al., 2017a). A number of authors have recognized direct but complex relationships among LST, soil water status, vegetation density, and SEB from local to global scales (e.g., Carlson et al., 1981, 1994, Idso et al., 1975, Monteith, 1981).

Contactless sensors (i.e., thermal cameras and infrared radiometers, IRR) and wired sensors (such as thermocouple and resistive temperature detector) are usually adopted for measuring LST at different spatial scales for vegetation/soils monitoring applications. Applications of the thermal domain to precision agriculture varies in function of the platform where the sensor is mounted. Thus, for instance, satellite platforms have been most commonly used for $\mathrm{ET}_{\mathrm{c}}$ estimation applications (Bastiaanssen et al., 1998b; Allen et al., $2007 \mathrm{~b})$. Nevertheless, the boom of unmanned aerial vehicle $\left(\mathrm{UAV}_{\mathrm{s}}\right)$ in the last years with the consequent improvement of spatial resolution, has increased the interest of researchers to use this type of platforms for $\mathrm{ET}_{\mathrm{c}}$ determination and precision irrigation (Liang et al., 2021, Riveros-Burgos et al., 2021). On the contrary, thermal images obtained from on-ground, UAV or airborne are generally used for determining crop water status (Ben-Gal et al., 2009; Cohen et al., 2012), delineating crop management zones (Cohen et al., 2017; Rouze et al., 2021) and identifying and quantifying pest diseases (Zarco-Tejada et al., 2018; Poblete et al., 2021).

Thermal cameras and IRR are sensitive to infrared radiation from 8 to $14 \mu \mathrm{m}$ (atmospheric window) in order to minimize the atmosphere influence (amount of water vapor and carbon dioxide) and provide high-accuracy LST measurements. Specifically, thermal cameras capture the emitted energy and converts the energy received by each pixel to a scaled digital number (DN). Processing software then uses empirical calibration coefficients for converting the DN to LST at pixel level. Thus, thermal cameras provide continuous LST spatial information with the inconvenient of being representative of a certain instantaneous time. On the contrary, IRR provide only punctual information about the LST within the field of view (FOV) of the instrument, but they are able to register continuously on time LST information. They can be typically fixed in situ and/or portable for on field data collection.

Several uncertainties are associated with the retrieval of remotely sensed LST measurements. In fact, LST derived by ground-based, airborne, and space-borne RS sensors represents the aggregated radiometric temperature of all land surface components (i.e., soil and vegetation) within the sensor FOV (Krishnan et al., 2020). Also the geometric optics strongly influence RS-based LST measurements acquire from TIR instruments. Other uncertainties are related to the thermal camera calibration. In addition, LST measurements can be affected by external sources of interference (camera sensor noise, surface properties of vegetation and environmental conditions). Moreover, image acquisition time results critical to avoid LST heterogeneity caused by the shadows, which is minimized when the sun is relatively close to the solar zenith angle (Ramírez-Cuesta et al., 2017a).

Furthermore, the interpretation of thermal data suffers from the LST considerable temporal dynamism due to weather variables (such as wind speed, air temperature or cloud pres- 
ence). In this sense, Agam et al., (2013) evaluated the sensitivity of Crop Water Stress Index (CWSI, Idso et al., 1981) and LST to changes in solar radiation, observing a decrease in this index when solar radiation dropped due to clouds, specially under water stress conditions. However, no studies have assessed the influence that such drastic and instantaneous meteorological variations have on the energy balance components. This is of particular relevance when LST is derived from UAV platform where there can be variations in the environmental conditions during the acquisition of the images for the whole area of study.

The main objectives of this research were to investigate (i) how abrupt variations in meteorological conditions, especially solar radiation, influence LST obtained from proximal sensing; and (ii) the sensibility of sensible $(\mathrm{H})$ and LE fluxes of an orange orchard to this LST temporal dynamism. These objectives will allow to evaluate the hypothesis of whether on-ground and UAV derived instantaneous LST, H and LE data can be considered representative of a wider temporal scale under homogeneous and non-homogeneous meteorological conditions.

\section{Materials and methods}

\section{Study site}

The study was performed in a 0.7 ha orange orchard located in Southern Italy (Eastern Sicily, Lentini, SR; 37²0’12.65” N, 1453’33.04” E, WGS84; Fig. 1). At the study site, orange trees (Citrus sinensis (L.) Osbeck cv "Tarocco Sciara") were planted in 2010 with a framework of $6 \mathrm{~m} \times 4 \mathrm{~m}$. Average ( \pm standard error) tree height and trunk and canopy diameters in 2020 were $4.5 \mathrm{~m}( \pm 0.27 \mathrm{~m}), 0.15 \mathrm{~m}( \pm 0.05 \mathrm{~m})$ and $3.5 \mathrm{~m}( \pm 0.13 \mathrm{~m})$, respectively.

According to the Köppen-Geiger classification system, the study area climate is classified as hot-summer Mediterranean (Code Csa). Within the period 2002-2020, the average

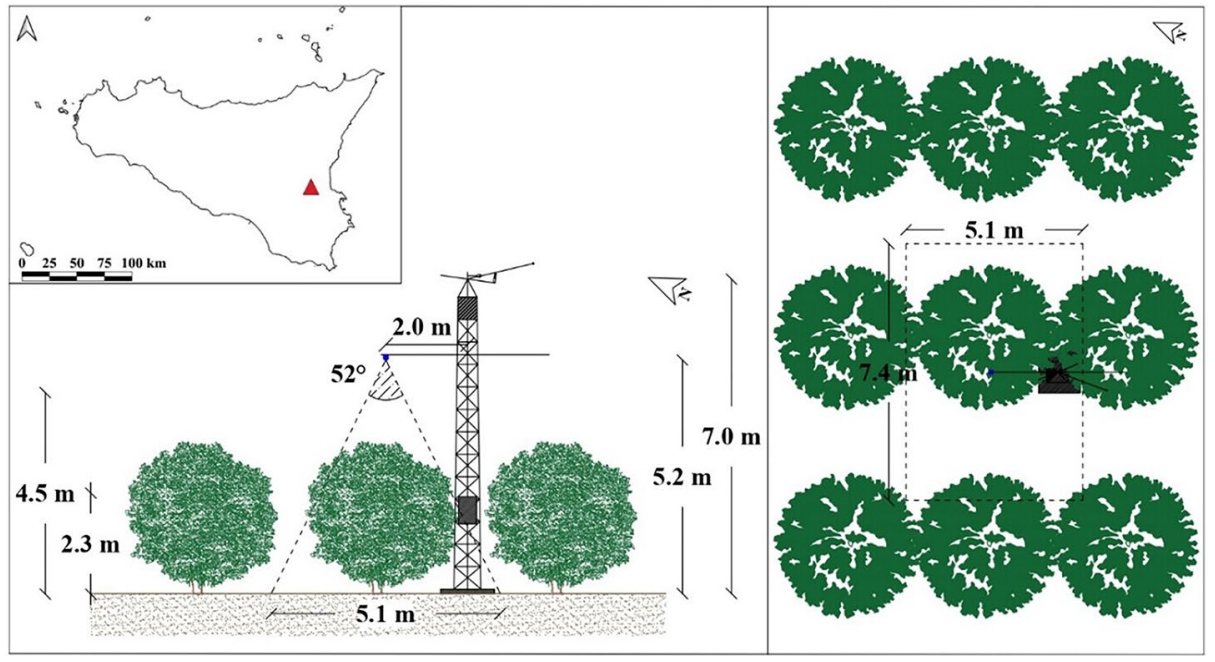

Fig. 1 Experimental design at the study area 
( \pm standard deviation) air temperature $\left(\mathrm{T}_{\mathrm{a}}\right)$, relative humidity $(\mathrm{RH})$ and wind speed $\left(\mathrm{u}_{2}\right)$ values were $21.2 \pm 7.4{ }^{\circ} \mathrm{C}, 59 \pm 9 \%$ and $1.96 \pm 0.04 \mathrm{~m} \mathrm{~s}^{-1}$ in spring - summer; and $15.4 \pm 6.1^{\circ} \mathrm{C}$, $70 \pm 2 \%$ and $1.77 \pm 0.11 \mathrm{~m} \mathrm{~s}^{-1}$, in winter - autumn. Average cumulative annual precipitation (P) and reference evapotranspiration $\left(\mathrm{ET}_{0}\right.$ ) ranged from 340 (in 2002) to 833 (in 2015) $\mathrm{mm}$ and from 1186 (in 2019) to 1420 (in 2012) mm, respectively, with averages values during the entire period of 580 and $1268 \mathrm{~mm}$, respectively. Based on these values, Aridity Index (Barrow, 1992) varies between 0.3 and 0.7 , corresponding to semi arid - dry sub humid climates (data obtained from Lentini meteorological station, 37²1'1.76"N 1454’29.05"E, WGS84; Servizio Informativo Agrometeorologico Siciliano, www.sias.regione.sicilia.it).

The soil has a sandy loam texture, with soil field capacity $\left(\theta_{\mathrm{FC}}\right)$ and permanent wilting point $\left(\theta_{\mathrm{WP}}\right)$ values of 0.28 and $0.14 \mathrm{~m}^{3} \mathrm{~m}^{-3}$, respectively. The soil bulk density is about $1.25 \mathrm{~g} \cdot \mathrm{cm}^{-3}$ (Aiello et al., 2014; Consoli et al., 2017).

\section{Eddy Covariance measurements}

An eddy covariance (EC) system was installed at the study site on a $7 \mathrm{~m}$ micrometeorological tower (Fig. 1) in 2016 (Saitta et al., 2020). Location requirements in terms of crop area representativeness, fetch/footprint and topography, were considered for EC tower installation (Vanella \& Consoli, 2018; Saitta et al., 2020). The EC system is composed of a 3-dimensional sonic anemometer (CSAT3-3D, Campbell Scientific Inc., Logan, Utah) for measuring at high frequency $(10 \mathrm{~Hz})$ the three wind components $\left(\mathrm{U}_{\mathrm{x}}, \mathrm{U}_{\mathrm{y}}, \mathrm{U}_{\mathrm{z}}, \mathrm{m} \mathrm{s}^{-1}\right)$, the sonic temperature $\left(\mathrm{T}_{\mathrm{a}, \mathrm{EC}}\right)$; and of an infrared open-path gas analyzer ( $\mathrm{Li}-7500$, Li-cor Biosciences Inc., Lincoln, Nebraska) for retrieving water vapor and carbon dioxide $\left(\mathrm{mg} \mathrm{m}^{-3}\right)$ concentrations. Additionally, the EC system incorporates a net radiometer (CNR-1 Kipp and Zonen, Delft, Netherlands) and three self-calibrated soil heat flux plates (HFP01SC, Hukseflux, Delft, Netherlands) for quantifying at low frequency $(30 \mathrm{~s})$ net radiation $\left(\mathrm{R}_{\mathrm{n}, \mathrm{EC}}\right.$; $\left.\mathrm{W} \mathrm{m}^{-2}\right)$ and soil heat fluxes $\left(\mathrm{G}_{\mathrm{EC}} ; \mathrm{W} \mathrm{m}^{-2}\right)$, respectively. Semi-hourly $\mathrm{R}_{\mathrm{n}, \mathrm{EC}}$ and $\mathrm{G}_{\mathrm{EC}}$ fluxes together with the high frequency components (i.e. wind speed, $\mathrm{T}_{\mathrm{a}, \mathrm{EC}}$ and water vapour density) were recorded in a CR1000 logger (Campbell Scientific Inc., Logan, Utah), and processed following EUROFLUX methodology (Aubinet et al., 2000). From EC, the sensible heat flux $\left(\mathrm{H}_{\mathrm{EC}} ; \mathrm{W} \mathrm{m}^{-2}\right)$ was calculated as:

$$
H_{E C}=\rho \cdot c_{p} \cdot \sigma_{w T}
$$

where, $\rho$ is the air density $\left(\mathrm{g} \mathrm{m}^{-3}\right), \mathrm{c}_{\mathrm{p}}$ is the air specific heat capacity at constant pressure $(\mathrm{J}$ $\mathrm{g}^{-1} \mathrm{~K}^{-1}$ ) and $\sigma_{\mathrm{wT}}$ is the covariance between the vertical wind speed and the air temperature $\left(\mathrm{m} \mathrm{s}^{-1} \mathrm{~K}\right)$.

The latent heat flux $\left(\mathrm{LE}_{\mathrm{EC}} ; \mathrm{W} \mathrm{m}^{-2}\right)$ was computed as:

$$
\mathrm{LE}_{\mathrm{EC}}=\lambda \cdot c_{p} \cdot \sigma_{w T}
$$

where, $\lambda$ is the latent heat of vaporization $\left(\mathrm{J} \mathrm{g}^{-1}\right)$; and $\sigma_{\mathrm{wq}}$ is the covariance between the vertical wind speed and water vapour density $\left(\mathrm{g} \mathrm{m}^{-2} \mathrm{~s}^{-1}\right)$. 


\section{Thermal data acquisition}

\section{Camera details}

The infrared camera used is an Optris PI 160 model (Optris GmbH, Berlin, Germany). The camera uses a $160 \times 120$ pixel @ $120 \mathrm{~Hz}$ Uncooled Focal Plane Array (UFPA) detector and has a spectral range of $7.5-13 \mu \mathrm{m}$, with an accuracy of $\pm 2{ }^{\circ} \mathrm{C} @ 23{ }^{\circ} \mathrm{C}$. The used lens guarantees a Field Of View (FOV) of $72^{\circ} \times 52^{\circ}$. The camera is based on standard Infrared Thermometry and the emissivity parameters it uses can be set between 0.1 and 1.1; it uses a unique calibration dataset based on camera Serial Number. Using a dedicated online tool (https://www.optris.global/optics-calculator, last accessed 23rd November 2021) it is possible to calculate all the required parameters. For a target distance of about $5.2 \mathrm{~m}$, it has $7.4 \mathrm{~m}$ (HFOV) and $5.1 \mathrm{~m}$ (VFOV), with a Pixel size: $39 \mathrm{~mm}$ (IFOV) at object level. The camera comes with a dedicated acquisition software (PIX Connect; Optris GmbH, Berlin, Germany) from Optris, that allows to set all the camera parameters and to capture images, numerical thermal data for each pixel in CSV format and video through an USB2 connection to a Windows PC. Specifically, a constant surface emissivity of 0.98 (corresponding to vegetation covers; Salisbury \& D’Aria 1992; Ramírez-Cuesta et el. 2017a) was applied to the entire image. This emissivity value was updated a posterior for bare soil covers (assigning a value of 0.96; Salisbury \& D'Aria 1992; Sobrino et al., 2009) identified during the segmentation process (Section "Images post-processing”).

\section{Experimental design}

Figure 1 shows the experimental design used for thermal data acquisition at the study area. The thermal camera (see Section "Camera details") was installed on a horizontal metal support of about $2 \mathrm{~m}$ long mounted on the EC tower, at $5.2 \mathrm{~m}$ height from the soil surface (and $3 \mathrm{~m}$ from the center of canopy height). These dimensions allowed covering a footprint, at soil level, of $5.1 \mathrm{~m}$ x $7.4 \mathrm{~m}$, which included both canopy and soil.

The trial was conducted for 5 days on June 2020 (days of the year, DOYs 161-164 and 167). A total of 96 thermal images were acquired around solar midday (between 12:50 and 13:10 CEST): 15 images during DOY 161, 20 images for DOYs 162, 163 and 167; and 21 images for DOY 166 (Table 1).

For each thermal camera acquisition time-step (Table 1), infrared measurements were acquired using a portable Apogee radiometer (Apogee Instruments, Inc. MI-210, Logan, Utah, USA). This infrared thermometer has a FOV of $22^{\circ}$ (half angle) and an accuracy

Table 1 Images acquisition time (DOY and hour), number of images acquired each day and sonic air temperature $\left(\mathrm{T}_{\mathrm{a}, \mathrm{EC}}\right)$ registered by the eddy covariance system during the acquisition period

\begin{tabular}{llll}
\hline Acquisition day (DOY) & $\begin{array}{l}\text { Hour interval } \\
\left(\mathrm{CEST}^{*}\right)\end{array}$ & $\begin{array}{l}\text { Number of } \\
\text { images }\end{array}$ & $\begin{array}{l}\mathrm{T}_{\mathrm{a}, \mathrm{EC}} \\
(\mathrm{K})\end{array}$ \\
\hline 161 & $12: 50-13: 10$ & 15 & 303.7 \\
162 & $12: 51-13: 10$ & 20 & 305.3 \\
163 & $12: 51-13: 10$ & 20 & 304.7 \\
164 & $12: 50-13: 10$ & 21 & 303.4 \\
167 & $12: 50-13: 09$ & 20 & 304.9 \\
\hline
\end{tabular}

*Central European Summer Time (UTC+02:00) 
of $0.3{ }^{\circ} \mathrm{C}$. It has a spectral range of $8-14 \mu \mathrm{m}$, which is comparable with that of the Optris camera used in this study (see "Camera details" section). In particular, at each time-step, three independent thermal measurements were acquired, representative of the tree canopy, shaded soil and sunny soil, respectively. The brightness temperature measured by the infrared radiometer $\left(\mathrm{T}_{\text {sensor }}\right.$, in $\left.\mathrm{K}\right)$ were afterward corrected for surface emissivity $(\varepsilon)$ as follows (Apogee Instruments 2020):

$$
L S T_{\text {rad }}=\sqrt[4]{\frac{T_{\text {sensor }}^{4}-(1-\epsilon) T_{\text {background }}^{4}}{\epsilon}}
$$

where $\mathrm{LST}_{\text {rad }}$ (in $\mathrm{K}$ ) is the instantaneous corrected LST of the target surface $\left(\mathrm{T}_{\mathrm{c}}, \mathrm{T}_{\mathrm{s}, \text { sha }}\right.$, and $\mathrm{T}_{\mathrm{s} \text { sun }}$, for tree canopy, shaded and sunny soil, respectively); and $\mathrm{T}_{\text {background }}$ (in $\mathrm{K}$ ) is the brightness temperature of the background (usually the sky). The values of $\varepsilon$ were assumed 0.98 for tree canopy and 0.96 for the soil component (Salisbury \& D'Aria, 1992; Sobrino et al., 2009).

\section{Thermal images post-processing}

Thermal data registered in CSV format using PIX Connect software were converted to TIFF format (Fig. 2a) using ArcGIS (10.5; Esri, Redlands, CA, USA). Then, isotherms at $0.1 \mathrm{~K}$ intervals were generated in order to facilitate the separation between vegetation and bare soil (Fig. 2b). This discrimination is based on the general theory of most edge detection methods (Prewitt, 1970; Sobel, 1970; Canny, 1986), which find the edges at those points where the gradient of the variable of interest (i.e. LST) is maximum. Specifically, the segmentation between vegetation and bare soil was performed by visually selecting threshold isotherm, located in the region of contact between both cover types, where the isotherms

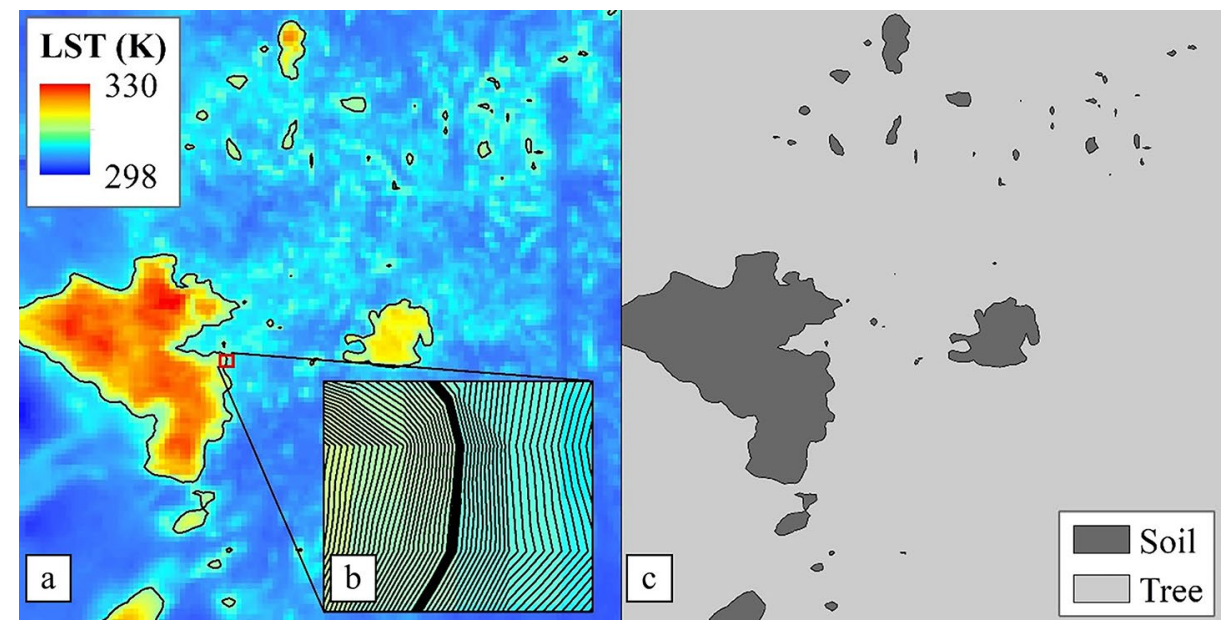

Fig. 2 (a) Thermal image retrieved from the thermal sensor; (b) $0.1 \mathrm{~K}$ interval isotherms with the selected threshold isotherm highlighted in thick black; and (c) cover type classification product derived from the segmentation process 
were closer to each other (Fig. 2b). Once both cover types were differentiated (Fig. 2c), their LST values were extracted and an emissivity correction was applied to the bare soil for considering an emissivity value of 0.96 (Salisbury \& D'Aria, 1992; Sobrino et al., 2009), consisting of an inversion of Eq. 3 using the $\mathrm{T}_{\text {background }}$ measured by the portable Apogee radiometer at each specific moment.

\section{Influence of surface temperature on crop evapotranspiration}

The SEB approach was followed for assessing how LST variations influence $\mathrm{ET}_{\mathrm{c}}$ fluxes. This approach describes the distribution of SEB fluxes toward and away from a reference surface as:

$$
R_{n}-G=H+L E
$$

where, $R_{n}$ is the net radiation, $G$ is the soil heat flux below the canopy, $H$ is the sensible heat flux from the canopy to the air, and LE is the latent heat flux to the air. All SEB components are expressed in $\mathrm{W} \mathrm{m}^{-2}$. Figure 3 summarises the methodology followed in the study to evaluate the effect of LST temporal dynamism on H and LE.

The $\mathrm{H}$ can be expressed in terms of temperature difference $\left(\mathrm{T}_{\mathrm{c}}-\mathrm{T}_{\mathrm{a}}\right)$ as:

$$
H=\rho \cdot c_{\mathrm{P}} \cdot \frac{T_{c}-T_{a}}{r_{a}}
$$

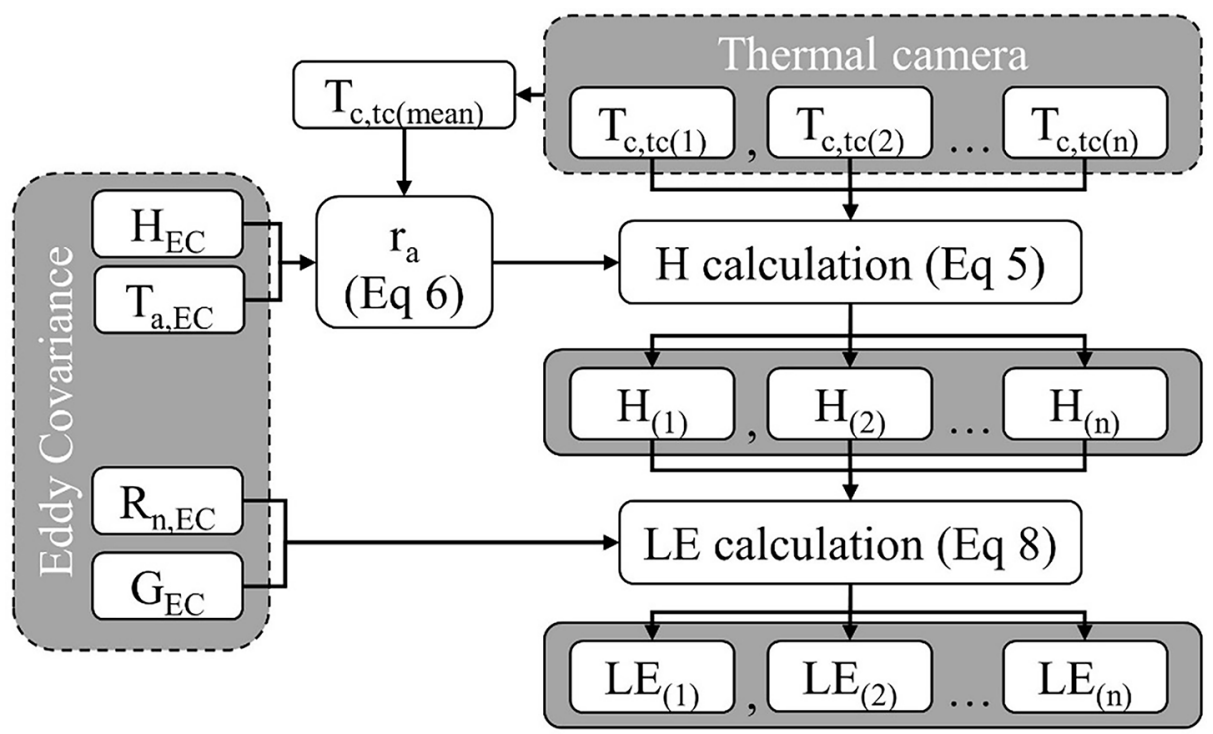

Fig. 3 Flow chart of the methodology followed to evaluate the effect of LST temporal dynamism on $\mathrm{H}$ and LE. Grey rectangles with dotted lines indicate the inputs (Eddy covariance and thermal camera, with EC and tc subindexes, respectively), whereas grey rectangles with continuous lines indicate final results. Blank rectangles correspond to intermediate results and the procedures used in the study. Numerical subindexes identify each individual image of the total number of images (n) acquired with the thermal camera 
where, $\rho$ is the air density $\left(\mathrm{kg} \mathrm{m}^{-3}\right), \mathrm{c}_{\mathrm{p}}$ is the specific heat of the air $\left(\mathrm{J} \mathrm{kg}^{-1}{ }^{\circ} \mathrm{C}^{-1}\right), \mathrm{r}_{\mathrm{a}}$ is the aerodynamic resistance $\left(\mathrm{s} \mathrm{m}^{-1}\right), \mathrm{T}_{\mathrm{c}}$ and $\mathrm{T}_{\mathrm{a}}$ are the canopy and air temperatures at the reference height $\left({ }^{\circ} \mathrm{C}\right)$, respectively (Jackson et al., 1981; González-Dugo et al., 2006).

By inverting Eq. 5 and using $\mathrm{H}$ computed by EC system $\left(\mathrm{H}_{\mathrm{EC}}\right.$; Eq. 1), $\mathrm{r}_{\mathrm{a}}$ can be retrieved as follows:

$$
r_{a}=\frac{\rho C_{p}\left(T_{c, t c}-T_{a, E C}\right)}{H_{E C}}
$$

where $\mathrm{T}_{\mathrm{a}, \mathrm{EC}}$ is provided by the high frequency 3-D sonic anemometer data and $\mathrm{T}_{\mathrm{c}, \mathrm{tc}}$ is retrieved from the thermal camera.

The term $T_{c, t c}$ was separately computed from the canopy $\left(T_{c}\right)$ and sunlit soil $\left(T_{s, \text { sunlit }}\right)$ temperatures extracted from the individual photographs, averaged by the vegetated fraction cover (VFC) of the experimental site, as:

$$
T_{c, t c}=T_{c} * V F C+T_{s, \text { sunlit }} *(1-V F C)
$$

Once $r_{a}$ has been calculated, $H$ was re-calculated from Eq. 5 for each thermal image timestep (1-min interval), assuming constant $r_{a}$; and including the $T_{c}$ from the specific image and $\mathrm{T}_{\mathrm{a}, \mathrm{EC}}$. Thus, an $\mathrm{H}$ value per minute was obtained (total of 16-20 values depending of the number of images per day; Table 1). From these $H$ values, LE was calculated at 1-min frequency as the residual of the SEB equation:

$$
L E=R_{n, E C}-G_{E C}-H
$$

where, $\mathrm{R}_{\mathrm{n}, \mathrm{EC}}$ and $\mathrm{G}_{\mathrm{EC}}$ are measured by $\mathrm{EC}$ system at the considered period.

\section{Results}

\section{Micrometeorological characterisation}

The temporal variation of the SEB components measured by the EC system during the reference period (Table 1) is shown in Fig. 4 flux-by-flux $\left(R_{n, E C}, H_{E C}, L_{E C}\right.$ and $\left.G_{E C}\right)$. Regarding $R_{n, E C}$ rates, maximum semi-hourly values of about $750-800 \mathrm{~W} \mathrm{~m}^{-2}$ were reached around midday of all considered days. However, the trend of the $\mathrm{R}_{\mathrm{n}, \mathrm{EC}}$ fluxes observed during the thermal images acquisition times (from 12:50 to 13:10 CEST) differed from one day to another. In this sense, DOYs 162-164 exhibited a smooth continuous shape of the $\mathrm{R}_{\mathrm{n}, \mathrm{EC}}$ rates, whereas in DOYs 161 and 167 a less steady time-response was observed with the presence of $R_{n, E C}$ decline peaks. It was specially relevant for DOY 162 , when a $R_{n, E C}$ decrease of $52 \%$ was observed in one hour (from $752 \mathrm{~W} \mathrm{~m}^{-2}$ at $11: 00$ to $358 \mathrm{~W} \mathrm{~m}^{-2}$ at 12:00; Fig. 4). Similar daily-trends were observed for $\mathrm{LE}_{\mathrm{EC}}$ and $\mathrm{H}_{\mathrm{EC}}$, with maximum semihourly values occurring at midday, being of around $200-300$ and $400 \mathrm{~W} \mathrm{~m}^{-2}$ for $\mathrm{LE}_{\mathrm{EC}}$ and $\mathrm{H}_{\mathrm{EC}}$, respectively. On the contrary, $\mathrm{G}_{\mathrm{EC}}$ depicted lower semi-hourly values, with maximum of 50-75 $\mathrm{W} \mathrm{m}^{-2}$ achieved around 17:00 $\mathrm{pm}$. 


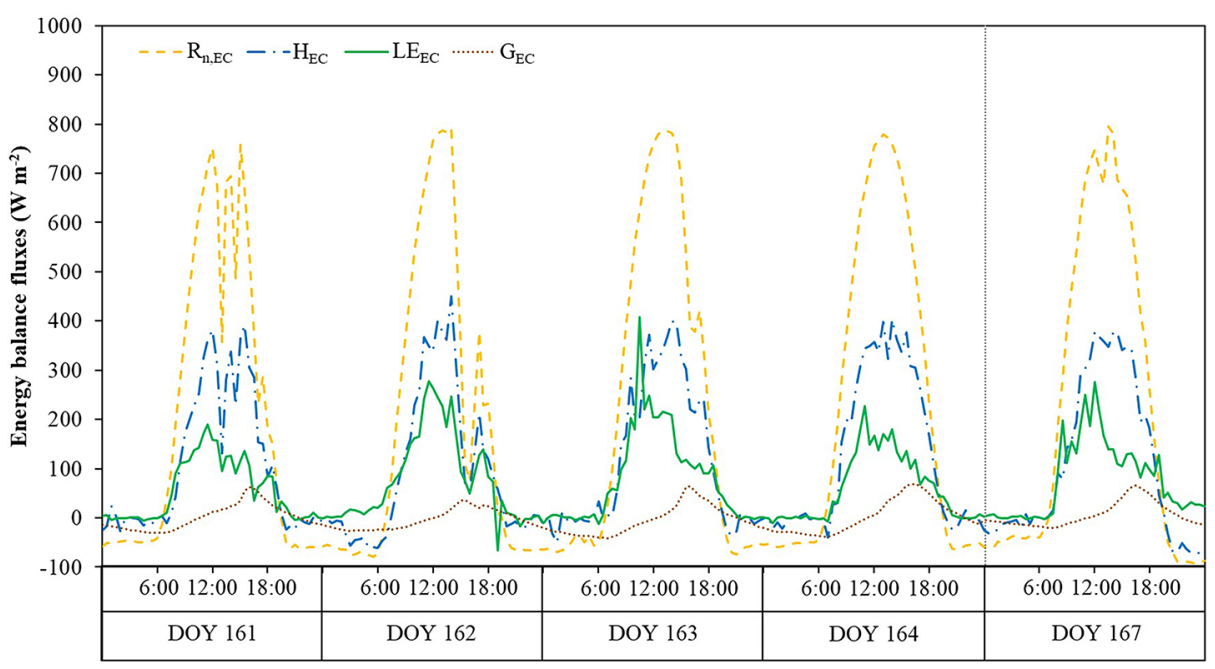

Fig. 4 Energy balance fluxes $\left(\mathrm{W} \mathrm{m}^{-2}\right)$ measured by the EC system during the thermal images acquisition days. $\mathrm{R}_{\mathrm{n}, \mathrm{EC}}, \mathrm{H}_{\mathrm{EC}}, \mathrm{LE}_{\mathrm{EC}}, \mathrm{G}_{\mathrm{EC}}$ refers to net radiation, sensible, latent and soil heat fluxes, respectively

\section{Surface temperature temporal variation}

The temporal evolution of the LST for sunlit $\left(\mathrm{T}_{\mathrm{s}, \mathrm{sun}}\right)$ and shaded soil $\left(\mathrm{T}_{\mathrm{s}, \text { sha }}\right)$ and tree canopy
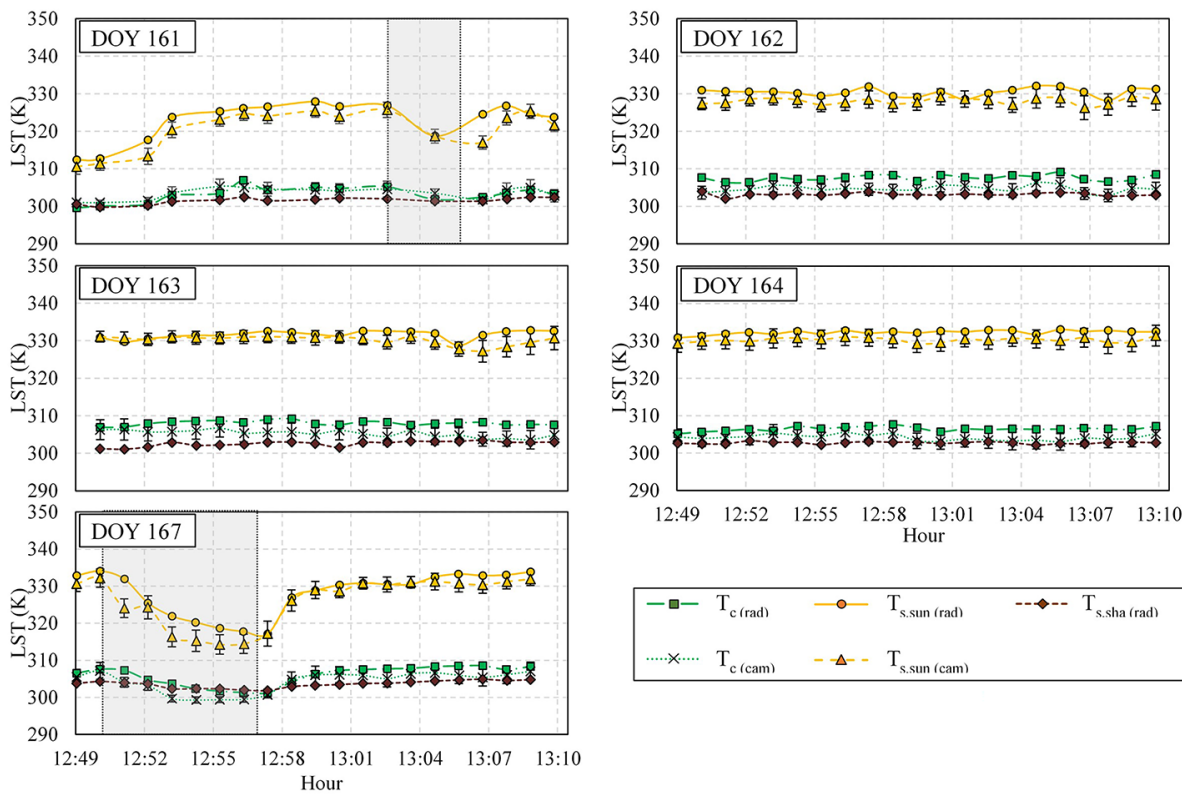

\begin{tabular}{|c|c|c|}
\hline$-\square-T_{c(\text { rad })}$ & $\begin{array}{ll}\mathrm{T}_{\text {s.sun (rad) }} \\
\end{array}$ & $\leadsto-T_{\text {s.sha (rad) }}$ \\
\hline$\cdots \times \cdots T_{c(c a m)}$ & $-\Delta^{-}-T_{\text {s.sun (cam) }}$ & \\
\hline
\end{tabular}

Fig. 5 Temporal evolution of the land surface temperature (LST) derived from the infrared radiometer (rad) and from the thermal camera (cam) for the sunny and shaded soil $\left(\mathrm{T}_{\mathrm{s}, \text { sun }}\right.$ and $\mathrm{T}_{\mathrm{s} \text {,sha }}$, respectively) and the tree canopy $\left(\mathrm{T}_{\mathrm{c}}\right)$. Shaded areas represent the presence of clouds when acquiring the measurements 
$\left(\mathrm{T}_{\mathrm{c}}\right)$ measured from the infrared radiometer ( $\left.\mathrm{rad}\right)$ and from the thermal camera (cam) during the considered DOYs is shown in Fig. 5. Nearly constant values were obtained for the DOYs 162, 163 and 164 for all surfaces (soil and vegetation), with LST variations in the 20-minutes periods considered of less than 4.0, 3.5 and $2.4 \mathrm{~K}$ for $\mathrm{T}_{\mathrm{s} \text {,sun }}, \mathrm{T}_{\mathrm{c}}$, and $\mathrm{T}_{\mathrm{s} \text {,sha, }}$, respectively. Contrarily, DOYs 161 and 167 presented a wider LST variation range for the same temporal period, reaching LST variations of 17.9, 7.8 and $3 \mathrm{~K}$ for $\mathrm{T}_{\mathrm{s} \text {,sun, }}, \mathrm{T}_{\mathrm{c}}$ and $\mathrm{T}_{\mathrm{s} \text {,sha, }}$, respectively (Fig. 5). This wider LST variation occurred in a small period of time, i.e. 7 and 4 min for DOYs 161 and 167, respectively.

When comparing the LST obtained from the infrared radiometer, $\mathrm{LST}_{(\mathrm{rad})}$ with that from the thermal camera, $\operatorname{LST}_{(\mathrm{cam})}$, similar values were registered $\left(\mathrm{R}^{2}\right.$ of 0.98$)$ with average differences among the two measurements techniques of $2 \mathrm{~K}$, both for $\mathrm{T}_{\mathrm{c}}$ and $\mathrm{T}_{\mathrm{s} \text {,sun }}$ (Fig. 6).

\section{Temperature impact on turbulent fluxes estimation}

Figure 7 shows the partition of the available energy $\left(R_{n, E C}-G_{E C}\right)$ between H and LE in each one of the evaluated days at the 20 -min period corresponding to the image acquisition. In

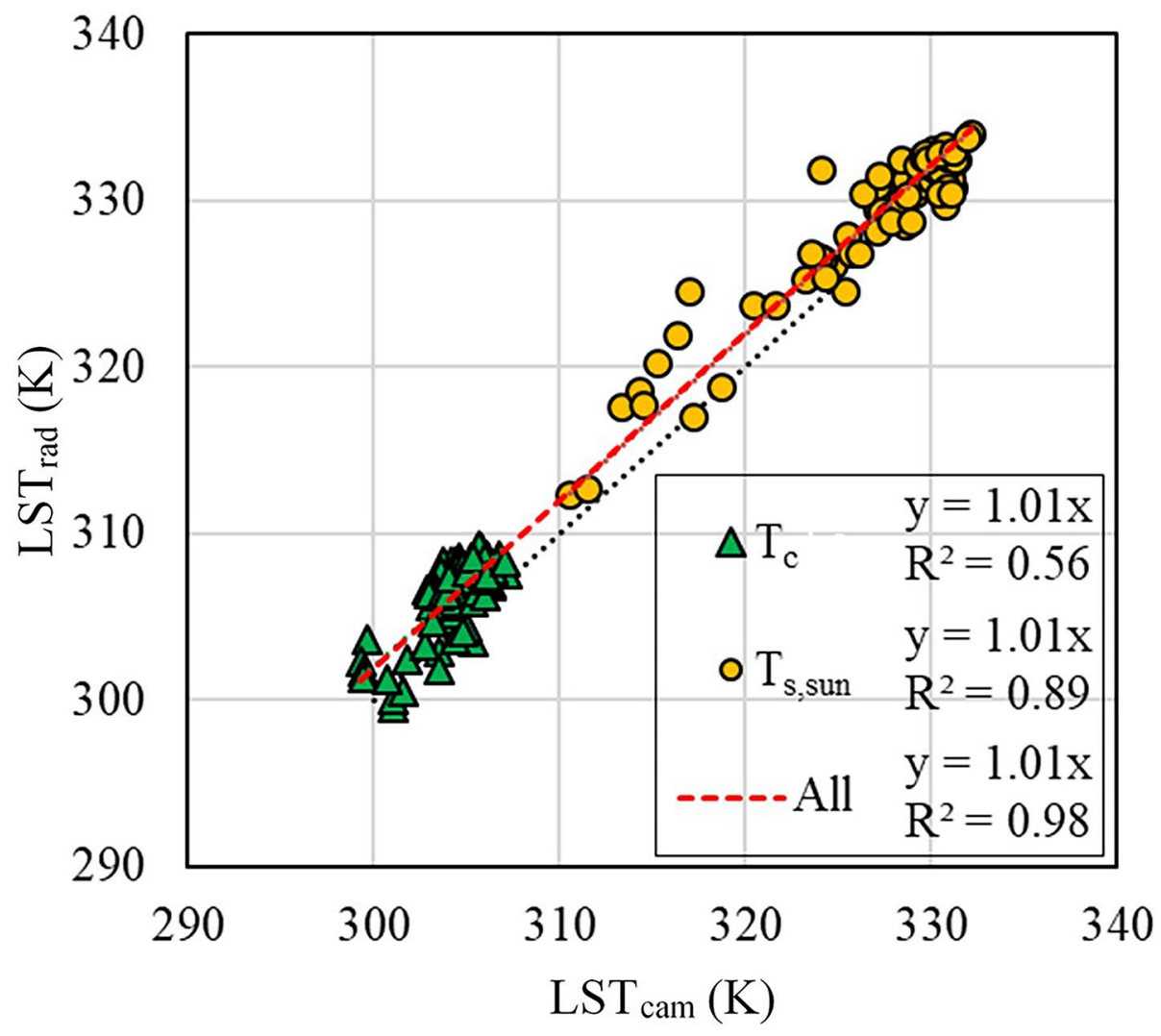

Fig. 6 Comparison between the surface temperature (both for the canopy, $\mathrm{T}_{\mathrm{c}}$, and the sunny soil, $\mathrm{T}_{\mathrm{s}, \text { sun }}, \mathrm{K}$ ) measured by the thermal camera $\left(\mathrm{LST}_{\text {cam }}\right)$ and the infrared radiometer $\left(\mathrm{LST}_{\mathrm{rad}}\right)$ during the reference period 

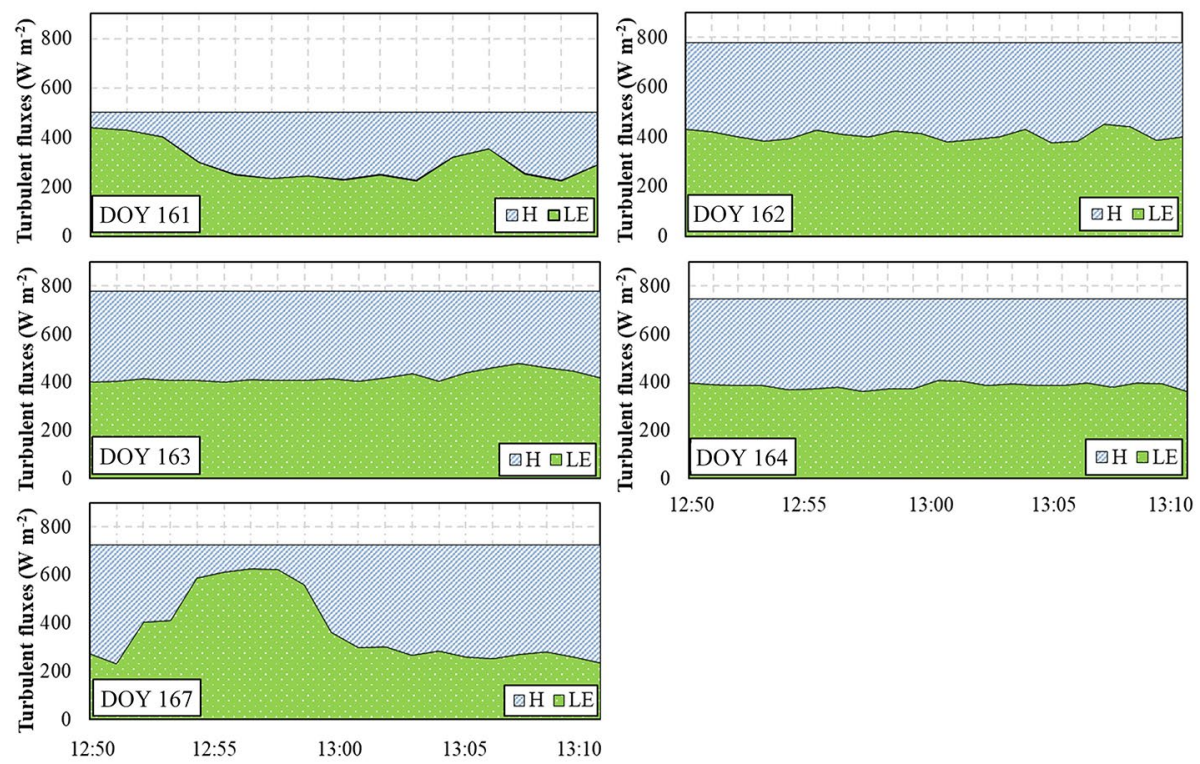

Fig. 7 Temporal evolution of the sensible (H) and latent (LE) heat fluxes derived from the combination of eddy covariance system and thermal imagery

particular, the available energy was $503,778,779,746$ and $723 \mathrm{~W} \mathrm{~m}^{-2}$ for DOYs $161-164$ and 167, respectively. A nearly constant temporal pattern was observed in $\mathrm{H}$ and LE at DOYs 162-164 with $\mathrm{H}$ values of about 371, 423 and $386 \mathrm{~W} \mathrm{~m}^{-2}$; LE values of 407, 423 and $386 \mathrm{~W} \mathrm{~m}^{-2}$, and standard deviations (SD) ranging from 12 to $23 \mathrm{~W} \mathrm{~m}^{-2}$ (Fig. 7). Contrarily, in DOYs 161 and 167 there were more important $\mathrm{H}$ and LE variations (SD=76-146 W $\mathrm{m}^{-2}$ ), with average $\mathrm{H}$ values of 206 and $353 \mathrm{~W} \mathrm{~m}^{-2}$; and average LE values of 298 and $370 \mathrm{~W} \mathrm{~m}^{-2}$, respectively (Fig. 7). These variations concentrated from 12:50 h to 12:55 h and from 13:03 $\mathrm{h}$ to 13:08 $\mathrm{h}$ in DOY 161; and from 12:50 $\mathrm{h}$ to 13:01 $\mathrm{h}$ in DOY 167. The rest of the time of these two days, $\mathrm{H}$ and LE remained almost constant, with absolute variations in comparison to their mean values of less than $6 \%$ and $7 \%$, respectively. Additionally, the stabilization of the fluxes occurred 3-4 min after the disappearance of intermittent clouds (i.e. when LE started to decline and H to increase; Fig. 7). Specifically, in DOY 161, even if clouds disappear at 13:06 h, H and LE fluxes did not stabilize until 13:09 h (Fig. 7). The same pattern was observed in DOY 167, when H and LE fluxes stabilized at 13:01 h although clouds disappeared at 12:57 h (Fig. 7).

\section{Discussion}

The use of thermography in precision agriculture, specially for detecting and monitoring plant water relations, has been a subject of research interest since the 60's (Tanner, 1963; Idso et al., 1981; Sepulcre-Cantó et al., 2006; Meron et al., 2010, 2013; Bellvert et al., 2014; Cohen et al., 2017; Gonzalez-Dugo et al., 2020). This approach is particularly interesting for mapping the variations in plant water status variables over large areas of study enabling 
the possibility of determining different orchard management zones. In addition, the remote estimation of $\mathrm{ET}_{\mathrm{c}}$ based on thermography will allow to derive protocols for a precision irrigation in terms of matching the water application to the average water requirements and by defining areas with different water needs. However, for this type of precision agriculture applications, some authors have hinted the importance of clear-sky conditions for acquiring quality thermal imagery (Ramírez-Cuesta et al., 2017a); but a deep analysis of how shortterm meteorological changes influence $\mathrm{ET}_{\mathrm{c}}$ has not been quantified yet.

Generally, micro-meteorological conditions gradually evolve during a day without experiencing abrupt changes, specially in Spring and Summer seasons, when the conditions are generally more steady (Ramírez-Cuesta et al., 2017b). However, there exist certain days when conditions are dynamic during the day and noteworthily vary even in short periods of time. In this sense, this study has shown that considerable changes in LST (e.g. up to $4 \mathrm{~K}$ for $\mathrm{T}_{\mathrm{s} \text {,sun, }}$ ) occurred even with homogeneous meteorological conditions (DOYs 162-164), being much more evident under fast-varying conditions (e.g. $17.9 \mathrm{~K}_{\text {for }} \mathrm{T}_{\mathrm{s} \text {, sun }}$ ).

Among the meteorological variables, solar radiation and wind speed are those that most influence LST variation, since they can experience abrupt changes within small periods of time. In this sense, the phenomena that most affect solar radiation is the cloud presence resulting in a decrease of the energy arriving to the surface causing the consequent drop in LST. Similarly, when the wind moves with a high speed, the heat stored on the surface is more easily taken away, and thus cooling the land cover. Wind speed also causes canopy structure changes, exposing previously shaded regions, resulting in that a lower LST is received by the sensor. On the contrary, the other meteorological variables, as $\mathrm{T}_{\mathrm{a}}$ or $\mathrm{RH}$, exhibit more gradual changes during the day, not leading to sudden changes in LST. Even if for some applications, $\mathrm{T}_{\mathrm{a}}$ can be used as a proxy of LST because $\mathrm{T}_{\mathrm{a}}$ measurements are commonly available and typically collected at weather stations, for other purposes, such as estimating biophysical attributes, $T_{a}$ is not representative of the LST because this can diverge substantially from $\mathrm{T}_{\mathrm{a}}$ (Jin \& Dickinson, 2010). The present study confirms the observations made by Jin \& Dickinson (2010) about that gradients in LST - $\mathrm{T}_{\mathrm{a}}$ are largest on calm days when aerodynamic conductances are lowest and still air layers develop adjacent to plant canopies and individual leaves. In this sense, Still et al., (2019) recommended the need of measuring complementary environmental properties for correcting interferences, especially $\mathrm{T}_{\mathrm{a}}$, during thermal camera acquisitions.

The LST response to short-term changes of meteorological conditions (i.e. presence of clouds) depended also on the different considered surface components (i.e. shaded or sunlit soil or tree canopy). In this sense, $\mathrm{T}_{\mathrm{s} \text {,sun }}$ responded quicker to meteorological changes than $\mathrm{T}_{\mathrm{s} \text {,sha }}$ and $\mathrm{T}_{\mathrm{c}}$, being $\mathrm{T}_{\mathrm{s} \text {,sun }}$ more consistent with $\mathrm{T}_{\text {air }}$ variations reaching also differences up to $25 \%$ as observed by $\mathrm{Ni}$ et al., (2019). In comparison to $\mathrm{T}_{\mathrm{s} \text {,sun }}, \mathrm{T}_{\mathrm{c}}$ variations were smoothed since plants require more time for auto-regulating the stomatal aperture/closure. The timelag until initial stomatal opening can be different for each individual stoma (Steppe et al., 2006). However, when considering $T_{s, s h a}$, these LST variations were lower due to the fact that this surface is less exposed to meteorological changes than $T_{c}$ and $T_{s, \text { sun }}$. Thus, for instance, shaded soil will be less affected to solar radiation changes due to a momentary presence of clouds since shaded soil will remain always shaded, experiencing very small changes in its temperature. Thus, heterogeneous crops as the one studied here, where a large proportion of bare soil is directly exposed to solar radiation, will be more influenced by short-term meteorological conditions than homogeneous crops completely covering the 
soil surface. In this sense, it is expected that heterogeneous crops with natural vegetation between tree rows, less sensitive to meteorological variations than those with traditional tilling, although more research is needed to confirm this hypothesis.

It is well known the critical role that LST plays on computing ET $_{\mathrm{c}}$ by using energy balance models (Bastiaanssen, 1995; Norman et al., 1995; Anderson et al., 1997; Bastiaanssen et al., 1998a; Allen et al., 2007a). This kind of approaches requires from meteorological variables usually recorded in weather stations. Most of these weather stations provides agrometeorological variables at hourly/semi-hourly or daily scale, so meteorological changes occurring within these time intervals could be not captured. Results obtained in this work demonstrated that special attention need to be paid when combining hourly/semi-hourly averaged meteorological data with images acquired at a specific time. Thus, for instance, when a single averaged value of $\left(\mathrm{R}_{\mathrm{n}}-\mathrm{G}\right)$ is considered during a $20 \mathrm{~min}$ interval (i.e. at the frequency registered by the weather station; Fig. 7), it can be observed that $\mathrm{H}$ and LE energy balance components are quite dependent on short-term variations captured by the thermal sensor. Thus, changes of up to 26 and $19 \%$ in $\mathrm{H}$ and LE, respectively, were observed under homogeneous meteorological conditions; whereas $\mathrm{H}$ and LE variations up to 5 and 2.7 times, respectively, were reached under fast-varying meteorological conditions. It is important to note that the influence of solar radiation variations (i.e. cloud presence) on $\mathrm{H}$ and LE fluxes persisted 4-5 min after the clouds disappearance, which should be taken into account when planning a flight campaign even under homogeneous conditions. Such H and LE variations could be also influenced by the strong short-term stomatal oscillations when variations in solar radiation, air temperature, humidity, and wind speed occurs (Steppe et al., 2006; Maes \& Steppe, 2012; López-Bernal et al., 2018; Agam et al., 2013) observed that solar radiation reduction caused by clouds presence resulted in a CWSI decrease, also finding weaker correlation between this index and physiological measurements under cloudy conditions than under homogeneous clear conditions. Additionally, these authors also remarked the necessity of high radiometric resolution imagery and constant reference measurements when using CWSI for water status detection. It has led to search crop water status indexes less sensitive to meteorological conditions (Iseki et al., 2020). Those results evidence the extremely importance of taking the images when meteorological changes are not expected to occur during the interval between two consecutive meteorological variables registers. Otherwise, changes due to instantaneous disturbances could be wrongly associated to crop water status differences, especially when the study area is so large that it needs to be covered by several photograms. Even if this work includes only images taken on-ground, similar results are expected when using satellite images due to their instantaneous nature, although additional research is needed to confirm this assumption. However, satellite images taken at a given moment will consider a much larger area of study that when UAV-based images are processed. Therefore instantaneous changes in the surrounding conditions are much more likely to affect $\mathrm{ET}_{\mathrm{c}}$ estimation based on thermal imagery taken from UAV campaigns.

One of the main concerns when using remote sensing images (including satellite, airborne and UAV) for precision agriculture is that, commonly, it is assumed that the meteorological conditions at the time of the image are representative of those of the period registered by the weather station (i.e. semi hourly or hourly frequency), therefore, assuming that the available energy is constant within this temporal period. This limitation is even more severe in the case of satellite images, since, contrary to the temporal flexibility provided by UAVs, satellites have a fixed image acquisition schedule. A possible solution could be increasing 
the acquisition frequency of the weather station taken as reference (e.g. at $1 \mathrm{~Hz}$ ) to better describe the meteorological conditions at the acquisition time. However, it is only possible when the user has plenty capabilities to manage the weather station, which rarely occurs since, commonly, the weather stations used are part of an independent weather station network (public or private), not being possible to change the acquisition frequency. In this case, the installation of a radiometer on board the drone can be considered for calculating the relationship between the solar radiation at the time of the image acquisition and the solar radiation registered at hourly (or semi-hourly) frequency in the weather station. A similar procedure is often performed to up-scaling instantaneous ET values obtained at the image acquisition time to daily values Allen et al., 2007a; Jiménez-Bello et al., 2015).

\section{Conclusions}

The present study reveals and quantifies the main effects that short-term meteorological variations, especially solar radiation, have on land surface temperature and on the sensible and latent heat fluxes. Thus, the main conclusions are summarized as in the following:

- Sunny bare soil, reaching LST variations up to $17.9 \mathrm{~K}$ in a 7-min interval, resulted more susceptible to short-terms meteorological changes than tree canopy temperature (with maximum LST variations of $7.8 \mathrm{~K}$ );

- The variations in LST strongly influenced the turbulent heat fluxes estimations from SEB approaches, resulting in $\mathrm{H}$ and LE variations up to 5 and 2.7 times;

- Complementary and high frequency meteorological measurements are required to accurately consider the instantaneous meteorological conditions at the image acquisition time, specially for fast varying scenarios.

Acknowledgements This study was supported by the Research Project of National Relevance (PRIN 2017) titled "INtegrated Computer modeling and monitoring for Irrigation Planning in Italy - INCIPIT"; and by the project PRECIRIEGO RTC-2017-6365-2 financed by AEI with FEDER co-funds. The authors thank the Consiglio per la Ricerca in agricoltura e l'analisi dell'Economia Agraria, Centro di Ricerca Olivicoltura, Frutticoltura e Agrumicoltura (CREA-OFA) for their hospitality at the experimental site. J.M.R.-C. and D.V. acknowledge the postdoctoral financial support received from Juan de la Cierva Spanish Postdoctoral Program (IJC2020-043601-I), and from Programma Operativo Nazionale (PON) "Attraction and International Mobility" (AIM) 1848200-2 initiative, respectively.

Funding Open Access funding provided thanks to the CRUE-CSIC agreement with Springer Nature.

Open Access This article is licensed under a Creative Commons Attribution 4.0 International License, which permits use, sharing, adaptation, distribution and reproduction in any medium or format, as long as you give appropriate credit to the original author(s) and the source, provide a link to the Creative Commons licence, and indicate if changes were made. The images or other third party material in this article are included in the article's Creative Commons licence, unless indicated otherwise in a credit line to the material. If material is not included in the article's Creative Commons licence and your intended use is not permitted by statutory regulation or exceeds the permitted use, you will need to obtain permission directly from the copyright holder. To view a copy of this licence, visit http://creativecommons.org/licenses/by/4.0/. 


\section{References}

Agam, N., Cohen, Y., Alchanatis, V., \& Ben-Gal, A. (2013). How sensitive is the CWSI to changes in solar radiation? International journal of remote sensing, 34, 6109-6120

Aiello, R., Bagarello, V., Barbagallo, S., Consoli, S., Di Prima, S., Giordano, G., \& Iovino, M. (2014). An assessment of the Beerkan method for determining the hydraulic properties of a sandy loam soil. Geoderma, 235, 300-307. https://doi.org/10.1016/j.geoderma.2014.07.024

Allen, R. G., Pereira, L. S., Raes, D., \& Smith, M. (1998). Crop Evapotranspiration-Guidelines for Computing Crop Water Requirements-FAO Irrigation and Drainage Paper 56. FAO Rome, 300(9), D05109

Allen, R. G., Tasumi, M., \& Trezza, R. (2007a). Satellite-based energy balance for mapping evapotranspiration with internalized calibration (METRIC)- model. Journal of irrigation and drainage engineering, 133, 380-394. https://doi.org/10.1061/(ASCE)0733-9437(2007)133:4(380)

Allen, R. G., Tasumi, M., Morse, A., Trezza, R., Wright, J. L., Bastiaanssen, W. .. Robison, C. W. (2007b). Satellite-based energy balance for mapping evapotranspiration with internalized calibration (METRIC)-Applications. Journal of irrigation and drainage engineering, 133, 395-406. https://doi. org/10.1061/(ASCE)0733-9437(2007)133:4(395)

Allen, R. G., Pereira, L. S., Howell, T. A., \& Jensen, M. E. (2011). Evapotranspiration information reporting: I. Factors governing measurement accuracy. Agricultural Water Management, 98, 899-920. https://doi. org/10.1016/j.agwat.2010.12.015

Anderson, M. C., Norman, J. M., Diak, G. R., Kustas, W. P., \& Mecikalski, J. R. (1997). A two-source timeintegrated model for estimating surface fluxes using thermal infrared remote sensing. Remote Sensing of Environment, 60, 195-216. https://doi.org/10.1016/S0034-4257(96)00215-5

Apogee Instruments, Inc. (2020). Owner's manual. Infrared temperature meter. Models MI-210, MI-220, MI-230, and MI-2H0. Apogee Instruments, Inc. Logan. Utah 84321, USA

Aubinet, M., Grelle, A., Ibrom, A., Rannik, U., Moncrieff, J., Foken, T. ... Vesala, T. (2000). Estimates of the annual net carbon and water exchange of Europeran forests: the EUROFLUX methodology. Advances in Ecological Research, 30, 113-175. https://doi.org/10.1016/S0065-2504(08)60018-5

Barrow, C. J. (1992). In N. Middleton, \& D. S. G. Thomas (Eds.), World Atlas of Desertification (United Nations Environment Programme). Ed. London: Edward Arnold. https://doi.org/10.1002/ldr.3400030407)

Bastiaanssen, W. G. M. (1995). Regionalization of Surface Flux Densities and Moisture Indicators in Composite Terrain: a Remote Sensing Approach under Clear Skies in Mediterranean Climates. Wageningen University

Bastiaanssen, W. G. M., Menenti, M., Feddes, R. A., \& Holtslag, A. A. M. (1998a). A remote sensing surface energy balance algorithm for land (SEBAL). 1. Formulation. Journal of Hydrology, 212-213, 198-212. https://doi.org/10.1016/S0022-1694(98)00253-4

Bastiaanssen, W. G., Pelgrum, H., Wang, J., Ma, Y., Moreno, J. F., Roerink, G. J., \& Van der Wal, T. (1998b). A remote sensing surface energy balance algorithm for land (SEBAL).: Part 2: Validation. Journal of hydrology, 212, 213-229

Bellvert, J., Zarco-Tejada, P. J., Girona, J., \& Fereres, E. (2014). Mapping crop water stress index in a 'Pinotnoir'vineyard: comparing ground measurements with thermal remote sensing imagery from an unmanned aerial vehicle. Precision agriculture, 15, 361-376. https://doi.org/10.1007/s11119-013-9334-5

Ben-Gal, A., Agam, N., Alchanatis, V., Cohen, Y., Yermiyahu, U., Zipori, I. ... Dag, A. (2009). Evaluating water stress in irrigated olives: correlation of soil water status, tree water status, and thermal imagery. Irrigation Science, 27, 367-376

Canny, J. (1986). A computational approach to edge detection. IEEE Trans. Pattern Anal. Mach. Intell. PAMI, $-8,679-698$

Carlson, T. N., Dodd, J. K., Benjamin, S. G., \& Cooper, J. M. (1981). Satellite estimation of surface energy balance, moisture avail-ability and thermal inertia. Journal of Applied Meteorology, 20, 67-87. https:// doi.org/10.1175/1520-0450(1981)020\%3C0067:SEOTSE\%3E2.0.CO;2

Carlson, T. N., Gillies, R. R., \& Perry, E. M. (1994). A method to make use of thermal infrared temperature and NDVI measurements to infer surface soil water content and fractional vegetation cover. Remote sensing reviews, 9, 161-173. https://doi.org/10.1080/02757259409532220

Cohen, Y., Alchanatis, V., Prigojin, A., Levi, A., \& Soroker, V. (2012). Use of aerial thermal imaging to estimate water status of palm trees. Precision Agriculture, 13, 123-140

Cohen, Y., Alchanatis, V., Saranga, Y., Rosenberg, O., Sela, E., \& Bosak, A. (2017). Mapping water status based on aerial thermal imagery: comparison of methodologies for upscaling from a single leaf to commercial fields. Precision Agriculture, 18, 801-822. https://doi.org/10.1007/s11119-016-9484-3

Consoli, S., \& Vanella, D. (2014a). Mapping crop evapotranspiration by integrating vegetation indices into a soil water balance model. Agricultural Water Management, 143, 71-81. https://doi.org/10.1016/j. agwat.2014.06.012 
Consoli, S., \& Vanella, D. (2014b). Comparisons of satellite-based models for estimating evapotranspiration fluxes. Journal of Hydrology, 513, 475-489. https://doi.org/10.1016/j.jhydrol.2014.03.071

Consoli, S., Stagno, F., Vanella, D., Boaga, J., Cassiani, G., \& Roccuzzo, G. (2017). Partial root-zone drying irrigation in orange orchards: Effects on water use and crop production characteristics. European Journal of Agronomy, 82, 190-202. https://doi.org/10.1016/j.eja.2016.11.001

Crago, R. D. (1996). Conservation and variability of the evaporative fraction during the daytime. Journal of Hydrology, 180, 173-194. https://doi.org/10.1016/0022-1694(95)02903-6

Filgueiras, R., Mantovani, E. C., Althoff, D., Dias, S. H., \& Cunha, F. F. D. (2019). Sensitivity of evapotranspiration estimated by orbital images under influence of surface temperature. Engenharia Agrícola, 39, 23-32. https://doi.org/10.1590/1809-4430-eng.agric.v39nep23-32/2019

Gong, X., Liu, H., Sun, J., Gao, Y., \& Zhang, H. (2019). Comparison of Shuttleworth-Wallace model and dual crop coefficient method for estimating evapotranspiration of tomato cultivated in a solar greenhouse. Agricultural Water Management, 217, 141-153. https://doi.org/10.1016/j.agwat.2019.02.012

González-Dugo, M. P., Moran, M. S., Mateos, L., \& Bryant, R. (2006). Canopy temperature variability as an indicator of crop water stress severity. Irrigation Science, 24, 233. https://doi.org/10.1007/ s00271-005-0022-8

Gonzalez-Dugo, V., Zarco-Tejada, P. J., Intrigliolo, D. S., \& Ramírez-Cuesta, J. M. (2020). Normalization of the crop water stress index to assess the within-field spatial variability of water stress sensitivity. Precision Agriculture, 1-20. https://doi.org/10.1007/s11119-020-09768-6

Idso, S. B., Schmugge, T. J., Jackson, R. D., \& Reginato, R. J. (1975). The utility of surface temperature measurements for the remote sensing of surface soil water status. Journal of Geophysical Research, 80, 3044-3049. https://doi.org/10.1029/JC080i021p03044

Idso, S. B., Jackson, R. D., Pinter, P. J., Reginato, R. J., \& Hatfield, J. L. (1981). Normalizing the stressdegree-day parameter for environmental variability. Agricultural Meteorology, 24, 45-55. https://doi. org/10.1016/0002-1571(81)90032-7

Iseki, K., \& Olaleye, O. (2020). A new indicator of leaf stomatal conductance based on thermal imaging for field grown cowpea. Plant Production Science, 23, 136-147. https://doi.org/10.1080/13439 43X.2019.1625273

Jackson, R. D., Idso, S. B., Reginato, R. J., \& Pinter, P. J. Jr. (1981). Canopy temperature as a crop water stress indicator. Water resources research, 17, 1133-1138. https://doi.org/10.1029/WR017i004p01133

Jiménez-Bello, M., Castel, J. R., Testi, L., \& Intrigliolo, D. S. (2015). Assessment of a remote sensing energy balance methodology (SEBAL) using different interpolation methods to determine evapotranspiration in a citrus orchard. IEEE Journal of Selected Topics in Applied Earth Observations and Remote Sensing, 8, 1465-1477. doi: https://doi.org/10.1109/JSTARS.2015.2418817

Jin, M., \& Dickinson, R. E. (2010). Land surface skin temperature climatology: Benefitting from the strengths of satellite observations. Environmental Research Letters, 5, 044004. https://oi. org/10.1088/1748-9326/5/4/044004

Krishnan, P., Meyers, T. P., Hook, S. J., Heuer, M., Senn, D., \& Dumas, E. J. (2020). Intercomparison of In Situ Sensors for Ground-Based Land Surface Temperature Measurements. Sensors, 20, 5268. https:// doi.org/10.3390/s20185268

Leinonen, I., \& Jones, H. G. (2004). Combining thermal and visible imagery for estimating canopy temperature and identifying plant stress. Journal of experimental botany, 55, 1423-1431. https://doi. org/10.1093/jxb/erh146

Liang, W. Z., Possignolo, I., Qiao, X., DeJonge, K., Irmak, S., Heeren, D., \& Rudnick, D. (2021). Utilizing digital image processing and two-source energy balance model for the estimation of evapotranspiration of dry edible beans in western Nebraska. Irrigation Science: 1-15

Longo-Minnolo, G., Vanella, D., Consoli, S., Intrigliolo, D. S., \& Ramírez-Cuesta, J. M. (2020). Integrating forecast meteorological data into the ArcDualKc model for estimating spatially distributed evapotranspiration rates of a citrus orchard. Agricultural Water Management, 231, 105967. https://doi. org/10.1016/j.agwat.2019.105967

López-Bernal, A., García-Tejera, O., Testi, L., Orgaz, F., \& Villalobos, F. J. (2018). Stomatal oscillations in olive trees: analysis and methodological implications. Tree physiology, 38, 531-542. doi: https://doi. org/10.1093/treephys/tpx127

Maes, W. H., \& Steppe, K. (2012). Estimating evapotranspiration and drought stress with ground-based thermal remote sensing in agriculture: a review. Journal of Experimental Botany, 63, 4671-4712. https:// doi.org/10.1093/jxb/ers 165

Maltese, A., Awada, H., Capodici, F., Ciraolo, G., La Loggia, G., \& Rallo, G. (2018). On the use of the eddy covariance latent heat flux and sap flow transpiration for the validation of a surface energy balance model. Remote Sensing, 10, 195. https://doi.org/10.3390/rs10020195 
Meron, M., Tsipris, J., Orlov, V., Alchanatis, V., \& Cohen, Y. (2010). Crop water stress mapping for site-specific irrigation by thermal imagery and artificial reference surfaces. Precision agriculture, 11, 148-162. https://doi.org/10.1007/s11119-009-9153-x

Meron, M., Sprintsin, M., Tsipris, J., Alchanatis, V., \& Cohen, Y. (2013). Foliage temperature extraction from thermal imagery for crop water stress determination. Precision Agriculture, 14, 467-477. https://doi. org/10.1007/s11119-013-9310-0

Monteith, J. L. (1981). Evaporation and surface temperature. Quarterly Journal of the Royal Meteorological Society, 107, 1-27. https://doi.org/10.1002/qj.49710745102

Ni, J., Cheng, Y., Wang, Q., Ng, C. W. W., \& Garg, A. (2019). Effects of vegetation on soil temperature and water content: Field monitoring and numerical modelling. Journal of Hydrology, 571, 494-502. https:// doi.org/10.1016/j.jhydrol.2019.02.009

Norman, J. M., Kustas, W. P., \& Humes, K. S. (1995). A two-source approach for estimating soil and vegetation energy fluxes from observations of directional radiometric surface temperature. Agricultural and Forest Meteorology, 77, 263-293. https://doi.org/10.1016/0168-1923(95)02265-Y

Paço, T. A., Pôças, I., Cunha, M., Silvestre, J. C., Santos, F. L., Paredes, P., \& Pereira, L. S. (2014). Evapotranspiration and crop coefficients for a super intensive olive orchard. An application of SIMDualKc and METRIC models using ground and satellite observations. Journal of Hydrology, 519, 2067-2080. https://doi.org/10.1016/j.jhydrol.2014.09.075

Poblete, T., Navas-Cortes, J. A., Camino, C., Calderon, R., Hornero, A., Gonzalez-Dugo, V. ... Zarco-Tejada, P. J. (2021). Discriminating Xylella fastidiosa from Verticillium dahliae infections in olive trees using thermal-and hyperspectral-based plant traits. ISPRS Journal of Photogrammetry and Remote Sensing, $179,133-144$

Prewitt, J. M. S. (1970). Object enhancement and extraction, Picture Processing and Psychopictorics. New York: Academic Press

Ramírez-Cuesta, J. M., Kilic, A., Allen, R., Santos, C., \& Lorite, I. J. (2017a). Evaluating the impact of adjusting surface temperature derived from Landsat 7 ETM + in crop evapotranspiration assessment using high-resolution airborne data. International Journal of Remote Sensing, 38, 4177-4205. https:// doi.org/10.1080/01431161.2017.1317939

Ramírez-Cuesta, J. M., Cruz-Blanco, M., Santos, C., \& Lorite, I. J. (2017b). Assessing reference evapotranspiration at regional scale based on remote sensing, weather forecast and GIS tools. International journal of applied earth observation and geoinformation, 55, 32-42

Ramírez-Cuesta, J. M., Mirás-Avalos, J. M., Rubio-Asensio, J. S., \& Intrigliolo, D. S. (2019). A novel ArcGIS toolbox for estimating crop water demands by integrating the dual crop coefficient approach with multi-satellite imagery. Water, 11, 38. https://doi.org/10.3390/w11010038

Ramírez-Cuesta, J. M., Allen, R. G., Intrigliolo, D. S., Kilic, A., Robison, C. W., Trezza, R. ... Lorite, I. J. (2020). METRIC-GIS: An advanced energy balance model for computing crop evapotranspiration in a GIS environment. Environmental Modelling \& Software, 131, 104770. https://doi.org/10.1016/j. envsoft.2020.104770

Rana, G., \& Katerji, N. (2000). Measurement and estimation of actual evapotranspiration in the field under Mediterranean climate: a review. European Journal of agronomy, 13, 125-153. https://doi.org/10.1016/ S1161-0301(00)00070-8

Riveros-Burgos, C., Ortega-Farías, S., Morales-Salinas, L., Fuentes-Peñailillo, F., \& Tian, F. (2021). Assessment of the clumped model to estimate olive orchard evapotranspiration using meteorological data and UAV-based thermal infrared imagery. Irrigation Science, 39, 63-80

Rouze, G., Neely, H., Morgan, C., Kustas, W., \& Wiethorn, M. (2021). Evaluating unoccupied aerial systems (UAS) imagery as an alternative tool towards cotton-based management zones. Precision Agriculture, 22, 1861-1889

Saitta, D., Vanella, D., Ramírez-Cuesta, J. M., Longo-Minnolo, G., Ferlito, F., \& Consoli, S. (2020). Comparison of orange orchard evapotranspiration by eddy covariance, sap flow, and FAO-56 methods under different irrigation strategies. Journal of Irrigation and Drainage Engineering, 146, 05020002. https:// doi.org/10.1061/(ASCE)IR.1943-4774.0001479

Salisbury, J. W., \& D'Aria, D. M. (1992). Emissivity of Terrestrial Materials in the 3-5 Microm Atmospheric Window. Remote Sensing of Environment, 42, 83-106. https://doi.org/10.1016/0034-4257(94)90102-3

Sepulcre-Cantó, G., Zarco-Tejada, P. J., Jiménez-Muñoz, J. C., Sobrino, J. A., De Miguel, E., \& Villalobos, F. J. (2006). Detection of water stress in an olive orchard with thermal remote sensing imagery. Agricultural and Forest Meteorology, 136, 31-44. https://doi.org/10.1016/j.agrformet.2006.01.008

Sobel, E. (1970). Camera Models and Machine Perception., PhD thesis. Stanford University, Stanford, California

Sobrino, J. A., Mattar, C., Pardo, P., Jiménez-Muñoz, J. C., Hook, S. J., Baldridge, A., \& Ibañez, R. (2009). Soil emissivity and reflectance spectra measurements. Applied optics, 48, 3664-3670. https://oi. org/10.1364/AO.48.003664 
Steppe, K., Dzikiti, S., Lemeur, R., \& Milford, J. R. (2006). Stomatal oscillations in orange trees under natural climatic conditions. Annals of Botany, 97, 831-835. https://doi.org/10.1093/aob/mcl031

Still, C., Powell, R., Aubrecht, D., Kim, Y., Helliker, B., Roberts, D. ... Goulden, M. (2019). Thermal imaging in plant and ecosystem ecology: applications and challenges. Ecosphere, 10, https://doi.org/10.1002/ ecs 2.2768

Tanner, C. B. (1963). Plant temperatures. Agronomy Journal, 55, 210-211. https://doi.org/10.2134/agronj19 63.00021962005500020043x

Vanella,D.,\&Consoli,S.(2018). Eddy Covariancefluxes versus satellite-based modelisation in adeficitirrigated orchard. Italian Journal of Agrometeorology, 2, 41-52. https://doi.org/10.19199/2018.2.2038-5625.041

Zarco-Tejada, P. J., Camino, C., Beck, P. S. A., Calderon, R., Hornero, A., Hernández-Clemente, R. ... Gonzalez-Dugo, V. (2018). Previsual symptoms of Xylella fastidiosa infection revealed in spectral planttrait alterations. Nature Plants, 4, 432-439

Zhang, K., Kimball, J. S., \& Running, S. W. (2016). A review of remote sensing based actual evapotranspiration estimation. Wiley Interdisciplinary Reviews: Water, 3, 834-853. https://doi.org/10.1002/wat2.1168

Publisher's Note Springer Nature remains neutral with regard to jurisdictional claims in published maps and institutional affiliations.

\section{Authors and Affiliations}

\section{Juan Miguel Ramírez-Cuesta ${ }^{1}$-Simona Consoli ${ }^{2} \cdot$ Domenico Longo $^{2}$. Giuseppe Longo-Minnolo ${ }^{3} \cdot$ Diego S. Intrigliolo $^{1} \cdot$ Daniela Vanella $^{2}$}

Juan Miguel Ramírez-Cuesta ramirezcuesta.jm@gmail.com

1 Department of Ecology, Desertification Research Centre, Desertification Research Centre (CIDE-CSIC-UV-GV), 46113Moncada, Valencia, Spain

2 Dipartimento di Agricoltura, Alimentazione, Ambiente (Di3A), Università degli Studi di Catania, Via S. Sofia, 100-95123 Catania, Italy

3 International Doctorate in Agricultural, Food and Environmental Science-Di3A, University of Catania, Catania, Italy 